\title{
Short-limb skeletal dysplasia with severe combined immunodeficiency
}

INSERM

\section{Source}

INSERM. (1999). Orphanet: an online rare disease and orphan drug data base. Short-limb skeletal dysplasia with severe combined immunodeficiency. ORPHA:935

Short-limb skeletal dysplasia with severe combined immunodeficiency is an extremely rare type of SCID (see this term) characterized by the classical signs of T-B- SCID (severe and recurrent infections, diarrhea, failure to thrive, absence of $\mathrm{T}$ and $\mathrm{B}$ lymphocytes) (see this term), associated with skeletal anomalies like short stature, bowing of the long bones and metaphyseal abnormalities of variable degree of severity. 